\title{
Experience With a New Device for Clearing Mucus From the Endotracheal Tube
}

\author{
Robert H Stone RRT and Stephen S Bricknell RRT
}

\begin{abstract}
Partial or total obstruction of an endotracheal tube (ETT) by mucus can cause severe respiratory distress, hypoxemia, or death. Signs of an obstructed ETT include increased ventilation pressure, changes in the ventilator graphics, $\mathrm{S}_{\mathrm{pO}_{2}}$ decrease, and cardiovascular changes. We present 3 patients whose ETTs were partially obstructed by mucus. In each case the patient displayed adverse effects from the obstruction, but once the obstruction was removed they showed dramatic improvement. In each case we used a new device (Rescue Cath, Omneotech, Tavernier, Florida) designed to remove mucus from the ETT lumen. The 3 cases demonstrate that the device is effective and capable of relieving the adverse effects of ETT mucus obstruction. Key words: endotracheal tube occlusion; тисиs plug. [Respir Care 2011;56(4):520-522. () 2011 Daedalus Enterprises]
\end{abstract}

\section{Introduction}

Occlusion of the endotracheal tube (ETT) by secretions (Fig. 1) can cause serious complications, including hypoxemia and death, and is an emergency that requires immediate resolution. Signs of ETT obstruction include sudden increase in ventilation pressure, extremely low tidal volume $\left(\mathrm{V}_{\mathrm{T}}\right)$, difficulty ventilating with a bagvalve-ETT, and inability to pass a suction catheter. ${ }^{1}$ The American Association for Respiratory Care Clinical Practice Guideline, "Removal of the Endotracheal Tube," states that "acute airway obstruction of the artificial airway due to mucus or mechanical deformation mandates immediate removal of the artificial airway." 2 The Rescue Cath (Omneotech, Tavernier, Florida) is an alternative method of restoring the airway without extubation, which risks compromising the patient's airway. It is an open catheter system for suctioning and removing secretions from the ETT lumen, and is a Class I

Robert H Stone RRT and Stephen S Bricknell RRT are affiliated with the Department of Respiratory Care, St Francis Medical Center, Cape Girardeau, Missouri.

The authors have disclosed no conflicts of interest.

Correspondence: Robert H Stone RRT, Respiratory Care, St Francis Medical Center, 211 St Francis Drive, Cape Girardeau MO 63703. Email: bstone@sfmc.net.

DOI: $10.4187 /$ respcare.00642 device, registered with the Food and Drug Administration. The Rescue Cath consists of a stiff catheter with a mesh-encased cleaning balloon at the distal end, a depth calibrator, balloon inflation syringe, handle, irrigation port, stopcock valve, and suction port (Fig. 2).

We obtained some Rescue Caths from a previous study done with Omneotech, at no cost to our facility. ${ }^{3}$ We received no monetary or other reimbursement from the company. Omneotech was given a copy of this report prior to publication. We report 3 cases that illustrate our initial clinical experience with the Rescue Cath.

\section{Case Report 1}

A 41-year-old male with severe alcoholic pancreatitis and hepatic failure was admitted to our facility. He had worsening abdominal pain, bloody emesis, fever, and chills. His vital signs were: temperature $36.7^{\circ} \mathrm{C}$, respiratory rate 16 breaths/min, blood pressure $80 / 55 \mathrm{~mm} \mathrm{Hg}$, and $\mathrm{S}_{\mathrm{pO}_{2}}$ $92 \%$ on non-rebreather mask. Chest radiograph showed "bilateral pulmonary edema with atelectasis versus infiltrates." He was admitted to the intensive care unit, where his respiratory status deteriorated, and he was eventually intubated and mechanically ventilated. Humidification was supplied by a heat-and-moisture exchanger (Aqua $+1 \mathrm{HS}$, Hudson RCI, Durham, North Carolina) for the first 4 days, and then was changed to a dual-heated-wire circuit (ConchaTherm Neptune, Hudson RCI, Durham, North Carolina). The inspired gas averaged $37.2^{\circ} \mathrm{C}$ at the $\mathrm{Y}$-piece. The ventilator settings were synchronized intermittent man- 


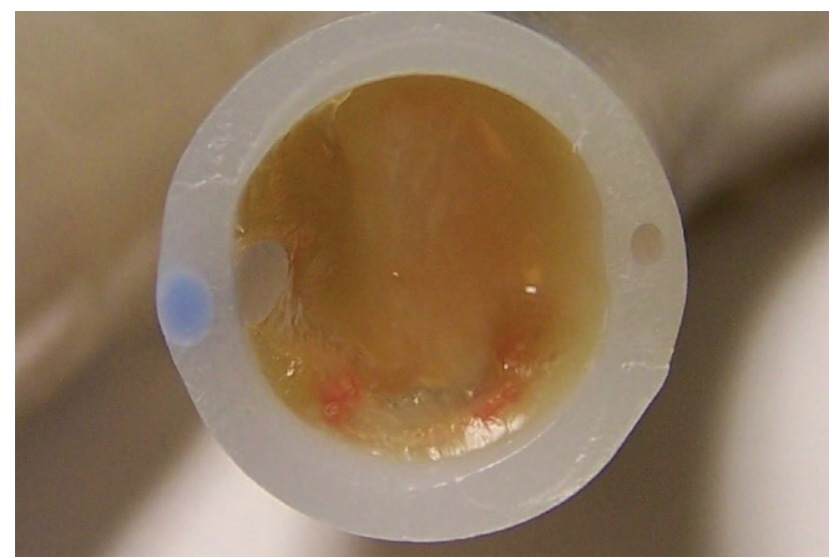

Fig. 1. Mucus occluding an 8.0-mm inner-diameter endotracheal tube, from a patient who was extubated and re-intubated due to respiratory distress.

datory ventilation (SIMV) at 10 breaths $/ \mathrm{min}, \mathrm{V}_{\mathrm{T}} 700 \mathrm{~mL}$ ( $9 \mathrm{~mL} / \mathrm{kg}$ ideal body weight), pressure support $10 \mathrm{~cm} \mathrm{H} \mathrm{H}_{2} \mathrm{O}$, PEEP $5 \mathrm{~cm} \mathrm{H} \mathrm{H}_{2} \mathrm{O}$, and $\mathrm{F}_{\mathrm{IO}_{2}}$ 0.60. The patient was mechanically ventilated through an $8.0-\mathrm{mm}$ innerdiameter ETT. After 6 days of mechanical ventilation, his status suddenly worsened. Peak airway pressure suddenly increased from the low 20 s to $48 \mathrm{~cm} \mathrm{H}_{2} \mathrm{O}$, respiratory rate increased from 18 breaths/min to 44 breaths/ min, $\mathrm{V}_{\mathrm{T}}$ decreased from $700 \mathrm{~mL}$ to $200 \mathrm{~mL}$, and $\mathrm{S}_{\mathrm{pO}_{2}}$ dropped from $99 \%$ to $88 \%$. We increased the $\mathrm{F}_{\mathrm{IO}_{2}}$ to 1.0 , but there was no change in $\mathrm{S}_{\mathrm{pO}_{2}}$. Increased use of accessory breathing muscles indicated increased respiratory effort. The attending respiratory therapist was unable to pass the suction catheter through the ETT. Saline was instilled and suctioned, with no change. At this time we used a Rescue Cath to clear secretions from the ETT and reestablish a patent airway. The first pass of the Rescue Cath obtained a large mucus plug. Within minutes the patient's respiratory rate decreased to 22 breaths/min, peak airway pressure decreased to $24 \mathrm{~cm} \mathrm{H}_{2} \mathrm{O}$, and there was a marked reduction in the use of accessory breathing muscles and respiratory effort. $\mathrm{S}_{\mathrm{pO}_{2}}$ gradually increased to $98 \%$, and we lowered $\mathrm{F}_{\mathrm{IO}_{2}}$ to 0.50 . The Rescue Cath cleared the ETT, prevented further physiologic deterioration, and improved the clinical situation, which prevented emergency extubation and re-intubation.

\section{Case Report 2}

A 61-year-old male with a history of hypertension, diabetes mellitus, peripheral vascular disease, congestive heart failure, obstructive sleep apnea, and COPD was admitted with pulmonary edema and bilateral pneumonia. On the 9th hospital day, his condition deteriorated and he was tracheally intubated with an $8.0-\mathrm{mm}$ inner-diameter

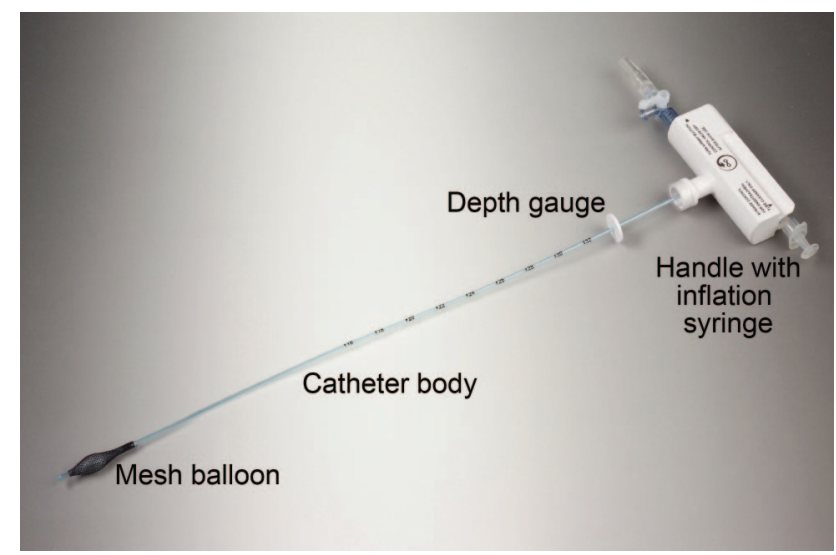

Fig. 2. Rescue Cath.

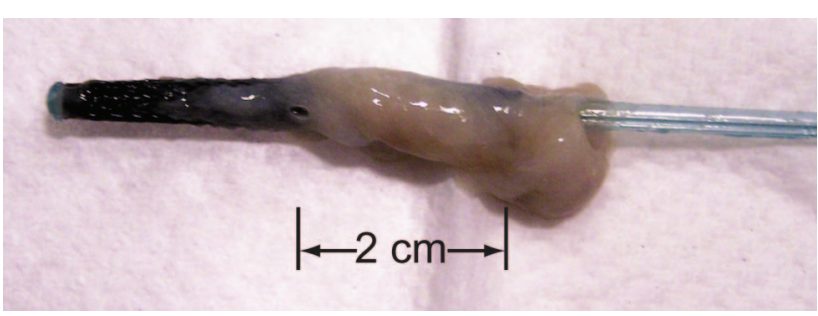

Fig. 3. Tip of a Rescue Cath after clearing mucus from an endotracheal tube.

ETT and mechanically ventilated with SIMV at 12 breaths/ min, $\mathrm{V}_{\mathrm{T}} 700 \mathrm{~mL}(8 \mathrm{~mL} / \mathrm{kg}$ ideal body weight), pressure support $10 \mathrm{~cm} \mathrm{H}_{2} \mathrm{O}$, PEEP $5 \mathrm{~cm} \mathrm{H}_{2} \mathrm{O}$, and $\mathrm{F}_{\mathrm{IO}_{2}}$ 0.60. A dual-heated-wire circuit (ConchaTherm Neptune, Hudson RCI, Durham, North Carolina) was used for humidification. On the 8th day of mechanical ventilation we started the weaning process, which progressed without difficulty. On the 10th day his ventilatory variables suggested he was ready for extubation, but then he became tachycardic, hypertensive, tachypneic (respiratory rate 30 breaths/min), diaphoretic, and had intercostal retractions and other signs of respiratory distress. We placed him back on an SIMV rate of 10 breaths/min and attempted ETT suctioning. When advancing the suction catheter, the respiratory therapist found substantial resistance at a specific point in the ETT, that was not noted earlier. The respiratory therapist obtained a Rescue Cath, pre-set the depth guide in accordance with the length of the ETT, advanced the catheter through the ETT, inflated the balloon and slowly removed the catheter. A large amount of mucus was removed (Fig. 3) and the patient's respiratory rate decreased to 16 breaths/ min, retractions subsided, and within 20 min his respiratory effort, heart rate, and blood pressure had all returned to baseline. His spontaneous $\mathrm{V}_{\mathrm{T}}$ was $635 \mathrm{~mL}$, minute volume was $9.6 \mathrm{~L}$, and $\mathrm{S}_{\mathrm{pO}_{2}}$ was $98 \%$. He was successfully extubated and placed on supplemental oxygen that day. 


\section{Experience With a New Device for Clearing Mucus From the Endotracheal Tube}

\section{Case Report 3}

An 81-year-old male suffered a tibial fracture in a motor vehicle accident. The fracture was immobilized nonoperatively at another facility, and he was discharged. Two days after being discharged he was readmitted to another facility because of shortness of breath and respiratory failure. On his second hospital day he was intubated with an 8.0-mm inner-diameter ETT and mechanically ventilated. He was then transferred to our facility. On admission he had: temperature $37.5^{\circ} \mathrm{C}$, heart rate 100 beats $/ \mathrm{min}$, respiratory rate 15 breaths/min, blood pressure $96 / 40 \mathrm{~mm} \mathrm{Hg}$, arterial $\mathrm{pH} 7.40, \mathrm{P}_{\mathrm{aCO}_{2}} 41 \mathrm{~mm} \mathrm{Hg}, \mathrm{P}_{\mathrm{aO}_{2}} 182 \mathrm{~mm} \mathrm{Hg}$, and $\mathrm{HCO}_{3} 24.7 \mathrm{mEq} / \mathrm{L}$. The ventilators settings were SIMV at 12 breaths/min, pressure support $10 \mathrm{~cm} \mathrm{H}_{2} \mathrm{O}$, PEEP $5 \mathrm{~cm} \mathrm{H}_{2} \mathrm{O}, \mathrm{V}_{\mathrm{T}} 700 \mathrm{~mL}$ ( $8.8 \mathrm{~mL} / \mathrm{kg}$ ideal body weight), and $\mathrm{F}_{\mathrm{IO}_{2}}$ 0.60. The inspired gas averaged $36.9^{\circ} \mathrm{C}$ at the $\mathrm{Y}$ piece. Humidification was via dual-heated-wire circuit (ConchaTherm Neptune, Hudson RCI, Durham, North Carolina). Chest radiograph showed bilateral infiltrates. After 9 days on mechanical ventilation, $\mathrm{S}_{\mathrm{pO}_{2}}$ dropped from $97 \%$ to $88 \%$, peak airway pressure increased from $28 \mathrm{~cm} \mathrm{H}_{2} \mathrm{O}$ to $60 \mathrm{~cm} \mathrm{H}_{2} \mathrm{O}$, and $\mathrm{V}_{\mathrm{T}}$ dropped from $700 \mathrm{~mL}$ to $120 \mathrm{~mL}$. The respiratory therapist had difficulty passing the suction catheter through the ETT. The Rescue Cath was employed and a large mucus plug was removed. The patient's condition immediately improved: $\mathrm{S}_{\mathrm{pO}_{2}}$ increased to $98 \%$, peak airway pressure dropped to $32 \mathrm{~cm} \mathrm{H}_{2} \mathrm{O}$, and $\mathrm{V}_{\mathrm{T}}$ increased to $650 \mathrm{~mL}$. Again, the Rescue Cath cleared the ETT and prevented emergency extubation and re-intubation.

\section{Discussion}

Our experience has been that secretions increase in viscosity and mucus builds up after several days of heat-andmoisture exchanger use, so we change to a heated-wire circuit after 4 days of heat-and-moisture exchanger use. At our facility we ventilate over 800 patients per year, with a median 3.3 ventilator days per patient. During our oneyear trial of the Rescue Cath we had 4 documented cases of ETT obstruction, which is within the expected range noted by Tobin. ${ }^{4}$

Another ETT secretion-clearance device mentioned in the literature is the Mucus Shaver, which was not commercially available for evaluation; however, we reviewed the studies by Kolobow et al, ${ }^{5}$ Berra et al, ${ }^{6}$ and Branson ${ }^{7}$ concerning the Mucus Shaver. All 3 studies found improvement in ETT mucus clearance in non-clinical, animal studies, but did not address mucus plugging, and the $\mathrm{Mu}-$ cus Shaver was not tested on viscous secretions. Kolobow stated that the "Mucus Shaver will be limited to ETT biofilm." Both the Mucus Shaver and the Rescue Cath are intended only for suction/clearance of the ETT lumen. The devices are similar in that they both use an inflatable balloon to create the contact between the mucus clearance mechanism and the ETT lumen. In both devices a gauge can be set to limit catheter insertion depth. The Mucus Shaver has 2 silicone rubber "shaving" rings attached to the balloon, whereas the Rescue Cath has a multi-mesh fiber surrounding the balloon. Another difference is that the Rescue Cath has a suction port and the Mucus shaver does not.

The proper technique for the Rescue Cath is quickly mastered. Following a demonstration and several practice attempts, a therapist can properly use the Rescue Cath. The depth calibrator is first adjusted to the proper length by aligning the catheter's numerical markings to the corresponding numerical markings on the ETT. The ventilator circuit is then disconnected and the catheter is advanced to the preset depth, where the balloon is inflated and the catheter is withdrawn from the ETT.

We had no complications with the use of the Rescue Cath. If the catheter balloon is inflated beyond the tip of the ETT, it is quickly deflated, repositioned, and re-inflated. We have used the Rescue Cath several times with great success, and it has also proven useful prior to bronchoscopy on intubated patients for removing inspissated secretions from the ETT lumen, improving visibility, reducing procedure time, and minimizing the need for irrigation.

Our experience has been that the Rescue Cath is safe and effective for removing mucus from the ETT while securely maintaining the ETT in place. The Rescue Cath may often obviate extubation of an obstructed ETT, as currently recommended in the American Association for Respiratory Care Clinical Practice Guideline. ${ }^{2}$

\section{REFERENCES}

1. Wilson AM, Gray DM, Thomas JG. Increases in endotracheal tube resistance are unpredictable relative to duration of intubation. Chest 2009;136(4):1006-1013.

2. American Association for Respiratory Care. AARC Clinical Practice Guideline: removal of the endotracheal tube. Respir Care 2007;52(1): 81-93.

3. Stone B, Bricknell SS, Morejon O. Bench study to evaluate the use of acoustic reflectometry to measure endotracheal tube obstruction. Respir Care 2007;52(11):1615.

4. Tobin MJ. Principles and practice of mechanical ventilation, 2nd edition. New York: McGraw-Hill; 2006.

5. Kolobow T, Berra L, Li Bassi G, Curto F. Novel system for complete removal of secretions within the endotracheal tube: the Mucus Shaver. Anesthesiology 2005;102(5):1063-1065

6. Berra L, Curto F, Li Bassi G, Laquerriere P, Baccarelli A, Kolobow T. Antibacterial-coated tracheal tubes cleaned with the Mucus Shaver: a novel method to retain long-term bactericidal activity of coated tracheal tubes. Intensive Care Med 2006;32(6):888-893.

7. Branson RD. Secretion management in the mechanically ventilated patient. Respir Care 2007;52(10):1328-1342. 